\title{
1-Phosphatidylinositol 4,5-Bisphosphate Phosphodiesterase Epsilon-1
}

National Cancer Institute

\section{Source}

National Cancer Institute. 1-Phosphatidylinositol 4,5-Bisphosphate Phosphodiesterase

Epsilon-1. NCI Thesaurus. Code C115069.

1-phosphatidylinositol 4,5-bisphosphate phosphodiesterase epsilon-1 (2302 aa, 259

$\mathrm{kDa}$ ) is encoded by the human PLCE1 gene. This protein is involved in phospholipid metabolism, signaling, cell growth and cell survival. 